\title{
O IMPACTO SOCIOAMBIENTAL DO IMÓVEL URBANO FRENTE ÀS CONSTRUÇÕES DESORDENADAS
}

\author{
Adriane Medianeira Toaldo ${ }^{1}$ \\ Lucas Saccol Meyne ${ }^{2}$
}

\begin{abstract}
Resumo: O presente estudo visa demonstrar a importância do meio ambiente, bem como o impacto socioambiental gerado com o desenvolvimento das cidades em suas construções desordenadas. Destacamse as inovações trazidas pela Lei $\mathrm{n}^{\circ} 10.257 / 01$, a qual versa sobre o Estatuto das Cidades, bem como as conseqüências das construções desordenadas e/ou em desacordo com o plano diretor. Dessa forma, a partir do Estatuto da Cidade, a política Urbana está ligada a Política Ambiental, buscando-se conciliar crescimento urbano, infra-estrutura e Função Social das cidades com qualidade ambiental. Será ainda desta feita, abordada a função socioambiental da propriedade frente aos anseios de uma crescente sociedade, para por fim justificar os malefícios que se apresentam na forma de reflexo socioambiental, na tentativa de resposta ao problema ora proposto, ou seja, as consequiências da construções desordenadas.
\end{abstract}

Palavras-chave: Impacto socioambiental. Imóvel urbano. Estatuto da Cidade. Construções desordenadas.

\section{INTRODUÇÃO}

Trata o presente trabalho do estudo da função socioambiental da propriedade urbana em nosso sistema jurídico. A importância do tema se apresenta com muita força pelo fato de que o meio ambiente é um bem universal, limitado e que pertence a todos, portanto é preciso protegê-lo e recuperá-lo, evitando desta forma que em benefício de alguns, todos padeçam em um futuro não muito distante, com os reflexos do desrespeito.

Será abordado o direito de propriedade, que é consagrado na Constituição Federal de 1988 em seu artigo 5 $5^{\circ}$ XXIII, "a propriedade atenderá a sua função social", e no artigo 170, II e III afirmando que a função social da propriedade deve respeitar princípios, como os de ordem econômica.

A utilização e o desfrute de um bem devem ser feitos de acordo com a conveniência social da utilização da coisa. O direito do dono deve ajustar-se aos interesses da sociedade. Em caso de utilização da propriedade em desacordo com a função social expressa na Lei Maior, acarreta em desordem de caráter socioeconômico na sociedade.

\footnotetext{
${ }^{1}$ Especialista em Direito Civil e Processo Civil pelo Instituto Ritter dos Reis, Canoas, RS. Mestre em Direito pela Universidade de Santa Cruz do Sul, RS, UNISC. Professora da Universidade Luterana do Brasil, ULBRA - Campus Santa Maria, RS. Advogada. adrianetoaldo@terra.com.br

${ }^{2}$ Acadêmico do Curso de Direito da Universidade Luterana do Brasil - Ulbra, Campus Santa Maria, RS. Lucas@familiasaccol.com.br
} 

III SEMINÁRII ECDLOGIA

POLÍTICA

A análise do Estatuto da Cidade é importante no estudo da função socioambiental da propriedade urbana, pois somente com a Constituição Federal de 1988 passou-se a falar em política de desenvolvimento urbano. Logo, o município tem competência nos seus limites territoriais, mas deve cuidar de todos os aspectos que afetam a qualidade de vida, dessa forma é o principal responsável pela implementação da política urbana. Como instrumento básico da política de desenvolvimento urbano, tem-se o plano diretor, obrigatório em cidades com mais de 20 mil habitantes, que definirá os mecanismos para o cumprimento da função social da cidade.

Prevista no artigo 182 da Constituição Federal de 1988 e regulamentada nos artigos 39 a 42 do Estatuto da Cidade, a Lei nº 10.257/2001, o Plano Diretor, sendo este um instrumento fundamental para o planejamento urbano por definir a política de desenvolvimento e expansão urbana, estabelece um modelo compatível com a proteção dos recursos naturais, em defesa do bem-estar da população.

O plano diretor deve reservar espaços para todas as atividades econômicas necessárias ao desenvolvimento da cidade, assim como prever a localização dos equipamentos públicos e comunitários que servirão de suporte para as políticas setoriais, como escolas, hospitais, praças, etc. $\mathrm{O}$ pleno direito à cidade inclui o direito à vida com dignidade, à moradia, à alimentação, à saúde e ao meio ambiente ecologicamente equilibrado, além da segurança de forma que a cidade somente cumpre sua função social quando os cidadãos possuem os chamados direitos urbanos.

A função social da cidade não pode deixar de englobar a sua função ambiental: "proteção do meio ambiente urbano e da qualidade de vida de seus habitantes". (LEMOS, 2008. p. 88)

Assim sendo, os cidadãos têm um papel a cumprir na implementação da função social, o controle popular é instrumento que permite a participação dos administrados junto ao poder público, conforme determina o art. 29, XII, da CF. O Estatuto da Cidade deve dar diretrizes para os planos diretores, de forma que fique no passado o crescimento desordenado das cidades, que tanto contribuiu para o descumprimento da função socioambiental da propriedade.

A função socioambiental da propriedade compreende uma série de direitos e deveres que cerceiam o uso, gozo e fruição do domínio ou posse de um determinado espaço público ou privado, seja ele rural ou urbano. 
Nos termos do art. 225 da Constituição Federal de 1988, a propriedade tem função social e tem função ambiental, ou seja, tem função socioambiental. As modificações apresentadas pelo Código Civil de 2002, no que tange ao direito de propriedade, trazem a função ambiental como elemento marcante deste direito. $\mathrm{O} \S 1^{\mathrm{o}}$ do art. 1.229 do Código Civil Brasileiro, que disciplina a propriedade conforme os avanços e necessidades sociais prescreve:

O direito de propriedade deve ser exercitado em consonância com suas finalidades econômicas e sociais e de modo que sejam preservados, de conformidade com o estabelecido em lei especial, a flora, a fauna, as belezas naturais, o equilíbrio ecológico e o patrimônio histórico e artístico, bem como evitada a poluição do ar e das águas.

Este dispositivo por si só deixa clara a necessidade da consonância entre as demandas sociais e o meio ambiente a ser protegido. Além de inserir a função social da propriedade, traz a função ambiental através de vários de seus componentes, como a proteção à flora e à fauna, a preservação das belezas naturais, a manutenção do equilíbrio ecológico, a preservação do patrimônio histórico e artístico, prescrevendo, por fim, que o uso da propriedade não provoque a poluição do ar e das águas, submetendo a propriedade às determinações presentes em legislação ambiental.

Sendo assim, o Direito de Propriedade passa de individualista e ilimitado (primeira geração) à Propriedade vinculada a uma Função Social (segunda geração) e, por fim, incorpora os valores ambientais, integrando ao seu conteúdo também uma Função Ambiental. O entendimento do Direito de Propriedade ligado a uma função ambiental é compartilhado por Antonio Herman V. Benjamin ao dizer que "ao lado da funcionalização social da Propriedade, com o novo texto constitucional deu-se também sua funcionalização ambiental”. (BENJAMIN, 1993. p. 79)

A função Socioambiental impõe limitações ao uso da propriedade urbana, requerendo do proprietário a adequação deste uso às exigências de ordem ambiental, em nome da proteção do patrimônio ambiental comum. No plano jurídico, Eros Roberto Grau analisa a função socioambiental:

A admissão do princípio da função social (e ambiental) da propriedade tem como conseqüência básica fazer com que a propriedade seja efetivamente exercida para beneficiar a coletividade e o meio ambiente (aspecto positivo), não bastando apenas que não seja exercida em prejuízo de terceiros ou da 
qualidade ambiental (aspecto negativo). Por outras palavras, a função social e ambiental não constitui um simples limite ao exercício do direito de propriedade, como aquela restrição tradicional, por meio da qual se permite ao proprietário, no exercício do seu direito, fazer tudo o que não prejudique a coletividade e o meio ambiente. Diversamente, a função social e ambiental vai mais longe e autoriza até que se imponha ao proprietário comportamentos positivos, no exercício do seu direito, para que a sua propriedade concretamente se adeqúe à preservação do meio ambiente. (GRAU, 1997. p. 77)

Assim sendo, para que se efetive a conciliação entre os princípios da ordem econômica estabelecidos constitucionalmente e os relativos aos direitos e garantias individuais referentes à propriedade, deve-se procurar harmonizar as vantagens individuais e privadas do proprietário e os benefícios socioambientais, que são o proveito coletivo. Essa é a propriedade que goza da tutela constitucional.

A função social do meio ambiente urbano está disposta no artigo 182, $\S 2^{\circ}$ da Constituição Federal, competindo ao município, mediante ações previstas no Plano Diretor, a fixação do conteúdo da função social da propriedade urbana.

Nessa perspectiva, o Plano Diretor tornou-se um instrumento importante para a proteção ambiental. No contexto de meio ambiente urbano, em que imperam a carência habitacional, a falta de saneamento básico, a falta de planejamento urbano, problemas de desemprego e organização social, compete ao Município a responsabilidade de transformar esse cenário e de estabelecer a função socioambiental da propriedade urbana. Dessa forma, por meio da Política de Desenvolvimento Urbano, a cargo do poder público municipal, advém o estabelecimento das regras para cumprimento da função socioambiental da propriedade.

Portanto, além de contemplar os interesses do proprietário sobre a propriedade, a função socioambiental deve levar em conta os interesses coletivos visando à promoção do bem comum, dando à propriedade melhor destinação do ponto de vista dos interesses sociais. "Isto significa que a função social da propriedade atua como fonte de imposição de comportamentos positivos - prestação de fazer, portanto, e não meramente, de não fazer - ao detentor do poder que deflui da propriedade", afirma Eros Roberto Grau. (GRAU, 2003. p. 213)

Entende-se que tanto o direito de propriedade quanto a função socioambiental, concorrem para assegurar a todos uma existência digna, razão pela qual a propriedade deve assegurar a realização dos interesses individuais, sociais e ambientais. 


\section{SIGNIFICADO E CONSEQÜÊNCIAS DAS CONSTRUÇÕES DESORDENADAS}

O chamado fenômeno da urbanização por que passaram e passam às cidades nos últimos anos, resultante, em boa parte, do êxodo rural, desenhou o perfil de nossa população, tornando-a predominantemente urbana. Nesse contexto, pode se afirmar que as cidades estão despreparadas para acolher o imenso contingente humano e absorver as demandas sociais, restando por serem previsíveis algumas conseqüências negativas, como o colapso do sistema de transportes, os congestionamentos no trânsito, o aumento de processos erosivos, os assoreamentos dos rios e a impermeabilização do solo como fatores desencadeantes das inundações, a proliferação de habitações subnormais, a ocupação de áreas de proteção ambiental, a precariedade do saneamento básico, a favelização, o desemprego e a violência.

$\mathrm{O}$ aumento da procura por espaços para habitação e trabalho multiplicou e muito os conflitos sociais na cidade. Tal situação se agrava, na seara da moradia. A população de baixa renda é empurrada para a periferia das cidades ou para localidades menos atrativas, sobretudo para lugares de topografia e condições geológicas menos vantajosas ou com restrições ambientais para uma regular ocupação, fazendo com que, nestas áreas, não se possam entram veículos de urgência e/ou emergência, haja dificuldades de acesso a escolas, saneamento de água e esgoto ineficaz ou ausente e demais necessidades básicas, deixando-as (pessoas) as margens da "sociedade verdadeira". (SAULE JÚNIOR, 1997. p. 61)

O meio ambiente urbano, devido a seu gritante e desordenado crescimento, restou por necessitar de uma produção legislativa específica, ou seja, o Estatuto da Cidade (Lei 10.257, de 10/07/01 - DOU de 11/07/01), referenciado outrora. Portanto, é tarefa dos urbanistas, administradores públicos e legisladores tutelar e conciliar as funções sociais da cidade em favor do bem-estar social. Para tanto, devem buscar a segurança nos espaços urbanos construídos fechados e abertos, nas edificações que compõem o primeiro grupo, utilizadas para uso prolongado (residências), ou para uso provisório, que agrupam grande número de pessoas (prédios comerciais e industriais, escritórios e repartições públicas, centros de lazer ou educacionais, etc.), visa-se garantir 
a segurança dos ocupantes mediante a edição de normas que assegurem a solidez e a estabilidade das construções, assim como dispositivos para sua proteção, na prevenção e combate a incêndios.

A necessidade da existência de um equilíbrio entre a preservação e o crescimento urbano, encontra como baliza o estudo prévio do impacto ambiental, segundo leciona Paulo Affonso Leme Machado:

O estudo deve ser anterior à autorização da obra ou atividade; deve ser obrigatoriamente exigido pelo Poder Público; para a instalação da obra e para o funcionamento da atividade podem ser exigidos estudos distintos; e o estudo deve ser revestido de publicidade. (MACHADO, 1992. p. 478)

Um ambiente urbano ecologicamente equilibrado também será saudável se for respeitado o uso dos imóveis de acordo com sua finalidade, com as restrições legais, em condições e horários determinados, implicando, no mais das vezes, conforto aos que residem no entorno. Uma das preocupações atuais dos habitantes das zonas urbanas refere-se à poluição sonora ou aos ruídos urbanos, causados principalmente quando o uso não respeita o lugar adequado e/ou o momento certo para seu exercício.

A racionalização do traçado urbano, o bom funcionamento dos serviços públicos, a correta distribuição da concentração demográfica, a criteriosa utilização das áreas públicas urbanas e a localização das atividades humanas, visa viabilizar o conforto da coletividade, mantendo a equação de equilíbrio entre população e ambiente, assim como entre área, habitantes e equipamentos urbanos, também compartilha do ideal da prevenção aliada ao eficaz planejamento.

A preocupação com a boa estética urbana revela-se, por exemplo, no desenho funcional do traçado viário da cidade, na moldura das edificações, assim como na comportada exploração publicitária feita por meio de faixas, cartazes, anúncios e pinturas nas fachadas, ou nos painéis e outdoors, que buscam conciliar o apelo visual e sua comunicação instantânea com os preceitos de ordenação paisagística.

Apesar das normas vigentes que asseguram, no plano ideal, a tutela ao meio ambiente natural e construído, verifica-se, no plano dos fatos, que a cidade legal constitui uma exceção, para não se dizer uma utopia, como se pode constatar na grande maioria dos municípios. Tudo se resume à falta de comando, de fiscalização, de exercício do poder de polícia pelas autoridades municipais sobre o processo de 
urbanização predatória e irracional que marca nossas grandes cidades. Às vezes essa irresponsabilidade é compartilhada com órgãos do Estado, nos casos de áreas de interesse metropolitano e/ou ambiental, como nas áreas de proteção aos mananciais por exemplo.

O deficiente funcionamento desse serviço público, que irradia efeitos danosos aos administrados difusamente considerados, ora decorre de fatores estruturais (de pessoal ou financeiro), ora da atitude moral das autoridades e servidores públicos (corrupção, prevaricação), ora da falta de vontade política de prefeitos em planejar ou prover a máquina administrativa de recursos humanos e materiais, ora de sua omissão ou descaso com o meio ambiente natural e urbano.

Os atos de degradação ambiental (desmatamentos, assoreamentos de cursos d'água, etc.) poderiam ser evitados em grande parte se o poder de polícia fosse eficaz, concreto e menos burocrático. Da mesma forma, o uso, a ocupação e o parcelamento do solo urbano seriam ordenados se houvesse fiscalização atuante por parte da Administração, de modo a inibir a clandestinidade. (ATHIAS, 1993. p. 237-249)

A desordenada ocupação do solo é protagonizada, por exemplo, pelos loteamentos clandestinos, que geram uma proliferação de habitações edificadas sem critérios técnicos de solidez e estabilidade trazendo insegurança e em condições subumanas e insalubres, o surgimento de focos de degradação do meio ambiente e da saúde (loteamentos em área de proteção ambiental), o adensamento populacional incompatível com o meio físico (má localização) e desprovido de equipamentos urbanos e comunitários, gerando o crescimento caótico das cidades; a marginalização dos seus habitantes com o incremento das desigualdades sociais e reflexos na segurança da população local e circunvizinha (violência, comércio de drogas).

Nesse contexto, a população sofre os efeitos e/ou consequiências das construções desordenadas, arcando com os custos das inevitáveis e "justificadas" intervenções do Poder Público para a sua regularização.Conflitos típicos das cidades desordenadas são travados diariamente por detentores de propriedades, entre si, assim como entre os que exercem atividades do mercado formal. Proprietários de imóveis desrespeitam as limitações de recuo e altura das construções, com edificações excessivamente altas que projetam sombras nas residências vizinhas, privando-as de insolação, aeração(ar) e iluminação. (ROLNIK, 1999. p. 126-133) 
O comércio confunde irregularmente o espaço das residências nas zonas em que as últimas deveriam predominar tudo sob os olhos complacentes da Administração. Formam-se corredores de lojas e escritórios em locais projetados para habitação, trazendo consigo tráfego, emissão de gases, barulho e agitação em detrimento do zoneamento, do sossego e do conforto de um bairro residencial, instala-se grande quantidade de antenas de telefonia celular nas diversas regiões da complexa cidade, no mais das vezes sem lei específica que delimite os locais propícios para tanto, quando não são clandestinas, sem estudos adequados que possam evitar eventuais danos à saúde, em face da propagação de ondas eletromagnéticas, frente a esses contrapontos, encontramos novamente o chamado Direito de Propriedade. . (FREITAS, 1999. P. 288-290)

A poluição sonora também multiplica-se nas mais variadas formas. Vão desde a instalação de bares nas zonas residenciais que, sem dispositivos de isolamento acústico, executam músicas com vibrações sonoras superiores aos decibéis permitidos, perturbando o sossego noturno. Passam pela sonoridade superlativa de cultos nos templos religiosos e dos ensaios animados das escolas de samba que estorvam o sono de todos. Chegam até as manifestações sindicais que pronunciam protestos em caminhões que circulam equipados com aparelhos de som, promovendo incômodo à concentração dos demais trabalhadores que laboram nas imediações.

A estética urbana é constantemente agredida por pichações em monumentos, prédios públicos e particulares, fachadas de edificações, pontes, viadutos, dentre outros. Placas e faixas de publicidade, algumas desproporcionais, outras aberrantes, que se multiplicam sem controle, são afixadas em postes de iluminação pública, nos suportes da sinalização de trânsito, no mobiliário urbano em geral, maltratando a paisagem. (FILOMENO, 2000. p. 13-31)

Aliado ao descaso das autoridades, grande parcela da população contribui com a imundície urbana ao sujar as vias públicas com restos de produtos, objetos e embalagens, agravando o entupimento dos bueiros e galerias de escoamento de águas pluviais que, ao lado do processo incontrolável de impermeabilização do solo, promovida em parte pelas construções, colaborando com as inundações periódicas dos centros urbanos, nas épocas das chuvas.

As áreas públicas são tratadas como coisa de ninguém, muitos são os exemplos das usurpações de bens públicos de uso comum do povo (ruas, avenidas, praças, áreas 
verdes e institucionais, áreas de lazer, jardins, passeios, praias, etc.), quase sempre toleradas ou consentidas pela Administração Pública. Invasões de inúmeras áreas públicas, para fins de moradia por famílias de baixa renda, contribuem com o aumento das favelas, algumas ainda, são estabelecidas sob pontes e viadutos, oferecendo risco difuso quando causam incêndios, abalando suas estruturas, trazendo transtornos à circulação da população. (FREITAS, 2000. P. 11-28)

O direito de livre trânsito pelos passeios cede espaço em favor das mesas instaladas nas calçadas, por bares, restaurantes e lanchonetes, que oferecem local aprazível sem se importar com pessoas portadoras de deficiência física e demais pedestres, dentre estes, idosos e crianças, que são obrigados a desviar e a perigosamente disputar espaços nas ruas com os automóveis.

Vendedores ambulantes (camelôs) desordenadamente tomam ruas, praças, calçadões e demais logradouros para comercializar produtos de duvidosa procedência, subtraindo o chão dos transeuntes. Veículos clandestinos de passageiros, taxis e vans de lotação, multiplicam-se pelas vias de circulação em acirrada disputa com ônibus e táxis legalizados, digladiando-se pela conquista da clientela.

Ou seja, ao invés da existência de uma análise comprometida com o interesse público, com os princípios da Constituição Federal que prega a erradicação da pobreza e das desigualdades sociais, e que objetiva a construção de uma sociedade justa, livre, solidária, com a promoção do bem de todos, sem preconceitos de origem, raça, cor, sexo, idade e qualquer outra forma de discriminação (art. $3^{\circ}, \mathrm{CF} / 88$ ), há de se concluir que, o isolamento de poucos privilegiados resta por marginalizar uma grande maioria, a qual em busca do seu discutido direito a moradia, sem outra alternativa, incorre na dita Construção Desordenada, que por fim atinge todos, indistintamente, ricos e pobres.

\section{CONSIDERAÇÕES FINAIS}

O assunto ora em destaque, tem por escopo elencar a função socioambiental da propriedade, em especial a do imóvel urbano, afetado pelas construções desordenadas, razão pela qual, fora ao longo deste estudo, tratado o Estatuto da Cidade, através da Lei 10.257, de 10 de julho de 2001, o qual veio corroborar com os também citados, artigos 182 e 183 da CF/88. 
Ao ser vista sob a ótica igualitária, regida pela nossa Carta Magna, todos são iguais perante a Lei, tendo todos direito à moradia digna, podendo desta feita se afirmar que as construções desordenadas são uma forma do ser homem buscar sua moradia de direito assegurada, tendo como sentimento maior a necessidade, o direito e a busca pela dignidade sua e de seus familiares, dentro de suas limitações financeiras e sociais.

Porém, em contraponto, estas áreas desordenadas muito embora se esteja na busca de um direito, acabam por voltar-se contra o próprio homem, ao passo que morar em uma região de preservação permanente e/ou risco, torna dificultoso todo e qualquer serviço social a que este tenha direito, ou seja, o acesso à educação, luz, água, esgoto e outros atendimentos indispensáveis, como veículos de emergência e urgência, os quais restam por não poder acessar a tais locais, gerando um transtorno a todos, em especial ao morador da área construída em desacordo com o planejamento, o qual não vislumbrou tais necessidades e sim somente buscou um local para residir, atendendo sua necessidade imediata.

Também constatou-se de forma clara o embate entre o direito a propriedade e seus limites, ou seja, até aonde a busca por tal direito poderia ou deveria ir, fora referido que o ser homem, por seu sentimento individualista e imediatista, está a colocar em risco as gerações futuras, através do reflexo de seus atos inconseqüentes.

Cuidou-se à exposição do Estatuto da Cidade, através da Lei 10.257/01, sendo esta um norte para todas as construções que se pretendam no meio urbano, pois tal dispositivo regula o Plano Diretor, peculiar a cada município, estabelecendo uma formatação ao meio urbano, para que não se incorra nas outrora referidas, construções desordenadas e sua gama de conseqüências.

O reflexo socioambiental das construções desordenadas, em desacordo com um Plano Diretor, se verifica diariamente, ou seja, basta sair de casa e olhar para qualquer direção, verificar-se-á alguma agressão ao meio ambiente, sejam ruas estreitas, ausência de passeio para pedestres, saneamento básico ausente, iluminação inexistente, dentre outros várias. Contrariedades ao Plano diretor. Aparentemente a gama de prejuízos que o homem se submete com tais desrespeitos é pequena, porém, a longo prazo, como será a ótica das gerações vindouras, o que restará para eles? É simples, basta que multipliquemos os problemas que hoje já enfrentamos, sejam, engarrafamentos viários, pois as ruas quando construídas, não se observou o planejamento adequado para a 


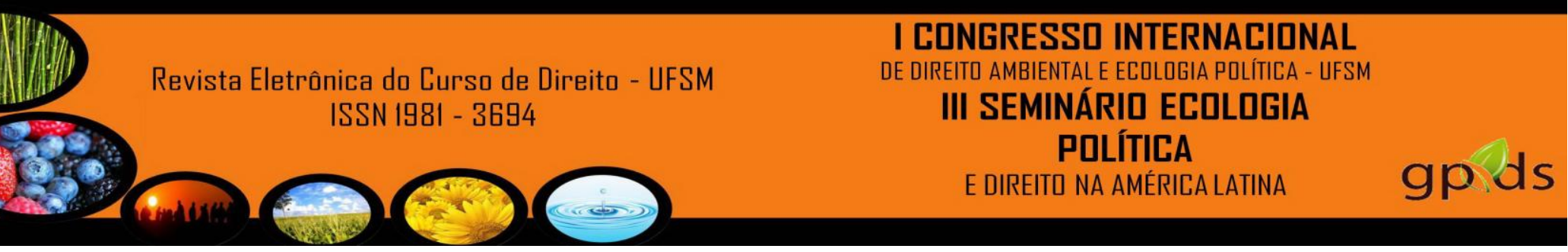

demanda futura, a dificuldade de acesso a escolas, veículos de emergência que não conseguem acessar vielas não planejadas, favelas urbanas que se formam todos os dias pelas invasões justificadas pela necessidade e claro, sem nenhum fim político.

Pessoas manipulam a desgraça das outras, seres semelhantes são marginalizados, desprezados, colocados as margens da sociedade, se amontoando em barracos, resguardados pelo também visto direito a propriedade.

Em suma, deste estudo resta à esperança que um dia possamos ter uma resposta exata para tais problemas, que exista um maior interesse em prol das pessoas e não só um fito econômico, que junto com o direito de moradia, seja estabelecida por regra a chamada dignidade, posta em nossa Carta Magna, onde dessa conjuntura verdadeiramente tenhamos uma sociedade planejada e instruída sobre seus direitos e deveres.

\section{REFERÊNCIAS BIBLIOGRÁFICAS}

ATHIAS, Jorge Alex Nunes. Responsabilidade civil e meio ambiente; breve panorama do Direito brasileiro. In: (Coord.). Dano Ambiental: prevenção, reparação e repressão. São Paulo: Revista dos Tribunais, 1993.

BENJAMIN, Antonio Herman V. Dano Ambiental: Prevenção, Reparação e Repressão. São Paulo: Revista dos Tribunais, 1993.

FILOMENO, José Geraldo Brito. As pichações em São Paulo: danos patrimoniais, urbanísticos e ambientais. Diagnóstico e propostas para sua inibição. In: Temas de Direito Urbanístico 2, co-edição Ministério Público de São Paulo e Imprensa Oficial do Estado de São Paulo. São Paulo: IMESP, 2000. p. 13-31.

FREITAS, José Carlos de. Dos interesses metaindividuais urbanísticos. In: Temas de Direito Urbanístico, co-edição Ministério Público de São Paulo e Imprensa Oficial do Estado de São Paulo. São Paulo: IMESP, 1999. p. 288-290.

Loteamentos clandestinos e suas modalidades fraudulentas: atuação preventiva dos agentes públicos. Revista de Direito Imobiliário, v. 23, n. 48, p. 11-28, jan.-jun. 2000 .

GRAU, Eros Roberto. Princípios fundamentais de direito Ambiental. Revista de Direito Ambiental, São Paulo, n. 02, 1997.

A ordem econômica na Constituição de 1988. 8. ed. São Paulo: Malheiros, 2003. 
